\title{
An Overview: Practice, Experience and Achievement of Polymer Flooding In Daqing Oilfield
}

\author{
Yubo Lan ${ }^{1, a}$, Qianru Li ${ }^{2, b}$, Li Kuang ${ }^{2, c}$ and Keman Li ${ }^{2, d}$ \\ ${ }^{1}$ Postdoctoral Workstation of Beijing Deweijiaye Science and Technology Corporation Ltd., Beijing, \\ China.100011 \\ ${ }^{2}$ College of Petroleum Engineering, Northeast Petroleum University. Daqing City, Heilongjiang \\ Province, 163318

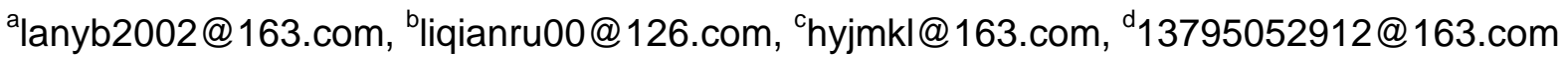

Keywords: Daqing oilfield; polymer flooding; polymer flooding parameters; producer injector spacing; achievement.

Abstract. Daqing oilfield was put into production in 1960. Excellent achievement is acquired. It has maintain the production of $5000 \times 10^{4}$ tons / year for 27 years and $5500 \times 10^{4}$ tons / year for 13 years. Main technologies adopted in Daqing oilfield include early-stage water flooding for pressure maintenance, separate-zone water injection and separate-zone production, division of series of development-zone, well infilling, chemical flooding and conventional stimulation measures such as hydraulic fracturing and acidizing. Research on polymer flooding was started in 1960s. This technology was widely put into industrialized application since 1996. Current proportion of production rate from polymer flooding is over $25 \%$. Technology of polymer flooding experienced laboratory experiment, pilot field test, industrialized field test and industrialized application, successively. In this paper, practice, experience and achievement of polymer flooding in Daqing oilfield were elaborated in view of class I reservoirs, class II reservoirs and class III reservoirs respectively. When it comes to class I reservoir, its effective thickness of single layer is more than 3 meters and effective permeability is greater than 0.3 . When it comes to class II reservoir, its effective thickness of single layer is between 1 meter and 3 meters and effective permeability is between 0.1 and 0.3 . Daqing oilfield use HPAM as polymer usually. When it comes to class III reservoir, its effective thickness of single layer is less than 1 meter and effective permeability is lower than 0.1 . Each types of reservoir were produced by polymer flooding in different period. Class I reservoir was put into production for polymer flooding at first stage. Concentration of polymer solution is $2000 \mathrm{mg} / \mathrm{L}$ and relative molecular weight of polymer is $2.5 \times 10^{7}$. Polymer dosage is $1100 \mathrm{PV} . \mathrm{mg} / \mathrm{L}$ and injection rate is $0.12 \mathrm{PV} / \mathrm{a}$. Injection-production well spacing is between 200 meters and 250meters. Class II reservoir was put into production with polymer flooding at second stage. Concentration of polymer solution is $1000 \mathrm{mg} / \mathrm{L}$ and relative molecular weight of polymer is between $1.2 \times 10^{7}$ and $1.6 \times 10^{7}$. Polymer dosage is $640 \mathrm{PV} . \mathrm{mg} / \mathrm{L}$ and injection rate is $0.14 \mathrm{PV} / \mathrm{a}$. Injection-production well spacing is between 150 meters and 175 meters. Class III reservoir was put into production with polymer flooding at third stage. Concentration of polymer solution is between $800 \mathrm{mg} / \mathrm{L}$ to $1000 \mathrm{mg} / \mathrm{L}$ and relative molecular weight of polymer is $5 \times 106$. Polymer dosage is 570PV.mg/L and injection rate is $0.25 \mathrm{PV} / \mathrm{a}$. Injection-production well spacing is between 100meters and 125meters. Each types of reservoir adopt five-spot polymer flooding well pattern. Perfect achievement from polymer flooding is acquired. Compared with water flooding, water cut is declined by $20 \%$ to the maximum, and recovery efficiency is increased by $10 \%$ for polymer flooding of class I reservoir. Water cut is declined by $11 \%$ to the maximum, and recovery efficiency is increased by $7.8 \%$ for polymer flooding of class II reservoir. Water cut is declined by $6 \%$ to the maximum, and recovery efficiency is increased by $5 \%$ for polymer flooding of class III reservoir. Daqing oilfield has accumulate lots of experience for polymer flooding in aspects of oil displacement mechanism, design of reservoir engineering program, adjustment of scheme, evaluation and prediction of technique indexes and distribution of remaining oil. 


\section{Introduction}

Daqing oilfield has entered high water cut development stage at present, polymer flooding has become general technology of EOR in Daqing oilfield [1]. This technology has been widely applied for class I reservoirs, an integrated theoretical system also been established [2]. For class II reservoirs and class III reservoirs. Daqing oilfield also carried out a series of laboratory experiment and pilot field test[3,4]. Through continuous summary test dynamic reflect characteristics, analyzes the existing problems in the process of polymer flooding, an integrated theoretical system also been established $[5,6]$. It is proved that each kind of reservoirs has acquired good effect, water cut rise rate was controlled, recovery ratio was improved. In this paper, we summarized the producer injector spacing and polymer flooding parameters in terms of class I reservoirs, class II reservoirs and class III reservoirs [7].

\section{Polymer Flooding Parameters of Class I Reservoirs}

Concentration of Polymer Solution. Through laboratory experiment, taking north-two-east eastern block as an example, four sets of schemes were designed to study concentration of polymer solution. Research results show that the greater the concentration of polymer solution, the higher the recovery efficiency. When concentration of polymer solution increase from $1000 \mathrm{mg} / \mathrm{L}$ to $1500 \mathrm{mg} / \mathrm{L}$, recovery efficiency increase by $2.8 \%$; When concentration of polymer solution increase from $1500 \mathrm{mg} / \mathrm{L}$ to $2000 \mathrm{mg} / \mathrm{L}$, recovery efficiency is increased by $4.6 \%$; When concentration of polymer solution increase from $2000 \mathrm{mg} / \mathrm{L}$ to $2500 \mathrm{mg} / \mathrm{L}$, recovery efficiency increase by $0.8 \%$, rise amplitude is indistinct. Therefore, for class II reservoirs, taking north-two-east eastern block as an example, concentration of polymer solution is $2000 \mathrm{mg} / \mathrm{L}$ [8].

Relative Molecular Weight of Polymer. Through same methods, taking north-two-east eastern block as an example, four sets of schemes were designed to study relative molecular weight of polymer.

Research results show that the greater the relative molecular weight of polymer, the higher the recovery efficiency. When relative molecular weight of polymer increase from $1.4 \times 10^{7}$ to $1.9 \times 10^{7}$, recovery efficiency increase by $1.5 \%$; When relative molecular weight of polymer increase from $1.9 \times 10^{7}$ to $2.5 \times 10^{7}$, recovery efficiency increase by $3.6 \%$; When relative molecular weight of polymer increase from $2.5 \times 10^{7}$ to $3.5 \times 10^{7}$, recovery efficiency increase by $0.5 \%$, rise amplitude is indistinct. Therefore, for class II reservoirs, taking north-two-east eastern block as an example, relative molecular weight of polymer is $2.5 \times 10^{7}[9]$.

Injection Rate of Polymer Solution. By using method of numerical simulation, four sets of computational schemes were designed to research injection rate of polymer solution.

Concentration of polymer solution is guaranteed as $2000 \mathrm{mg} / \mathrm{L}$, Relative molecular weight of polymer is $2.5 \times 107$, polymer dosage is $700 \mathrm{PV} . \mathrm{mg} / \mathrm{L}$, injection rate of polymer solution is designed as $0.10 \mathrm{PV} / \mathrm{a} 、 0.12 \mathrm{PV} / \mathrm{a} 、 0.14 \mathrm{PV} / \mathrm{a} 、 0.16 \mathrm{PV} / \mathrm{a}$ respectively[10].

Relationship between polymer flooding incremental oil and injection rate is shown in Fig.1. The greater the injection rate, the higher the degree of reserve recovery. But range ability is not obvious. With the increase of injection rate, elastic viscosity of polymer solution increased, shear viscosity of polymer solution decreased. However, the degree of increase is greater than the degree of decrease. So valid viscosity of polymer solution raised.

With the increase of injection rate, polymer flooding incremental oil increased gradually, rise amplitude is indistinct. 


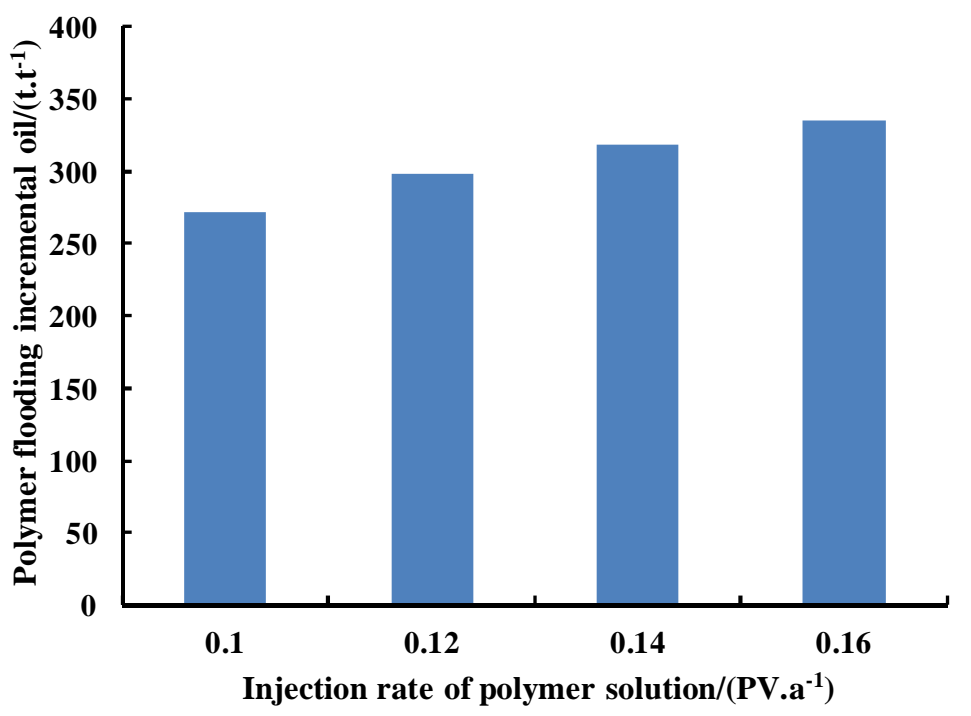

Fig.1 Relationship between polymer flooding incremental oil and injection rate

When injection rate is $0.16 \mathrm{PV} / \mathrm{a}$, maximum pressure of well head is $13.61 \mathrm{MPa}$, this pressure is greater than breakdown pressure of reservoir, which is $13.5 \mathrm{MPa}$. When injection rate is $0.12 \mathrm{PV} / \mathrm{a}$, maximum pressure of well head is $11.16 \mathrm{MPa}$, this pressure is lower than breakdown pressure of reservoir.

From what has been discussed above, considering degree of reserve recovery, polymer flooding incremental oil, breakdown pressure of reservoir and other technical indexes, injection rate of class I reservoir is $0.12 \mathrm{PV} / \mathrm{a}[11]$.

Polymer Dosage.By using method of numerical simulation, four sets of computational schemes were designed to research injection rate of polymer solution.

Concentration of polymer solution is guarantee as $2000 \mathrm{mg} / \mathrm{L}$, Relative molecular weight of polymer is $2.5 \times 10^{7}$, injection rate of polymer solution is $0.12 \mathrm{PV} / \mathrm{a}$, polymer dosage is designed as 900 PV.mg/L、 1100 PV.mg/L、1300 PV.mg/L、1500 PV.mg/L.[12]

Relationship between rise scope of recovery efficiency and polymer dosage is shown in Fig.2. With the increase of polymer dosage, recovery efficiency and the rise scope of recovery efficiency all increased. Because the greater the polymer dosage and the longer the coverage time, the better the effect of the remaining oil tapping, but the rise scope decreased gradually.

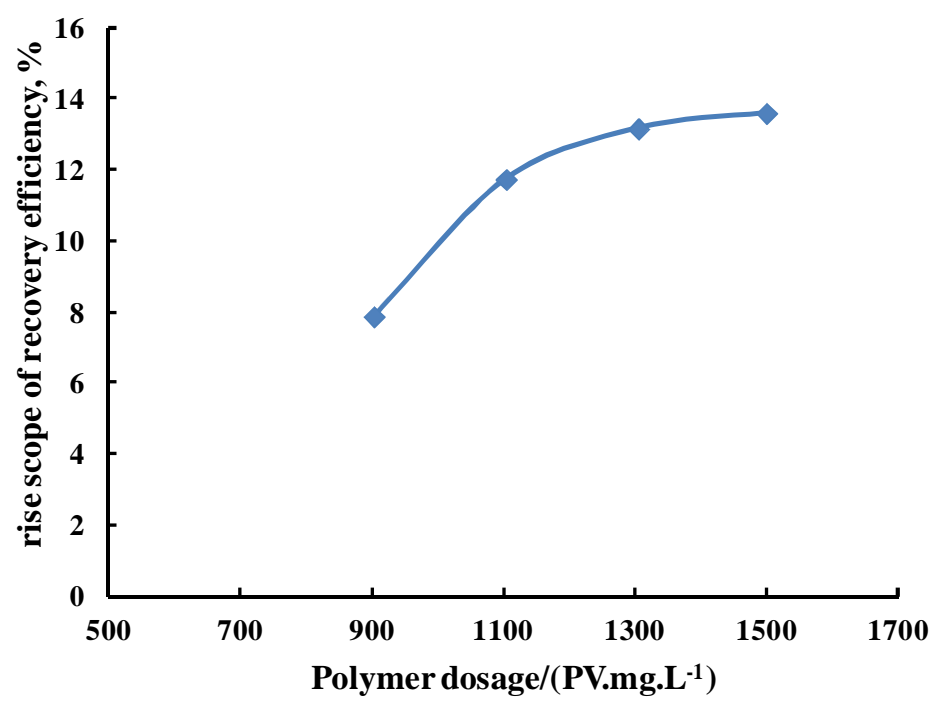

Fig.2 Relationship between rise scope of recovery efficiency and polymer dosage 
Relationship between polymer flooding incremental oil and polymer dosage is shown in Fig.3. With the increase of injection rate, polymer flooding incremental oil decreased gradually.

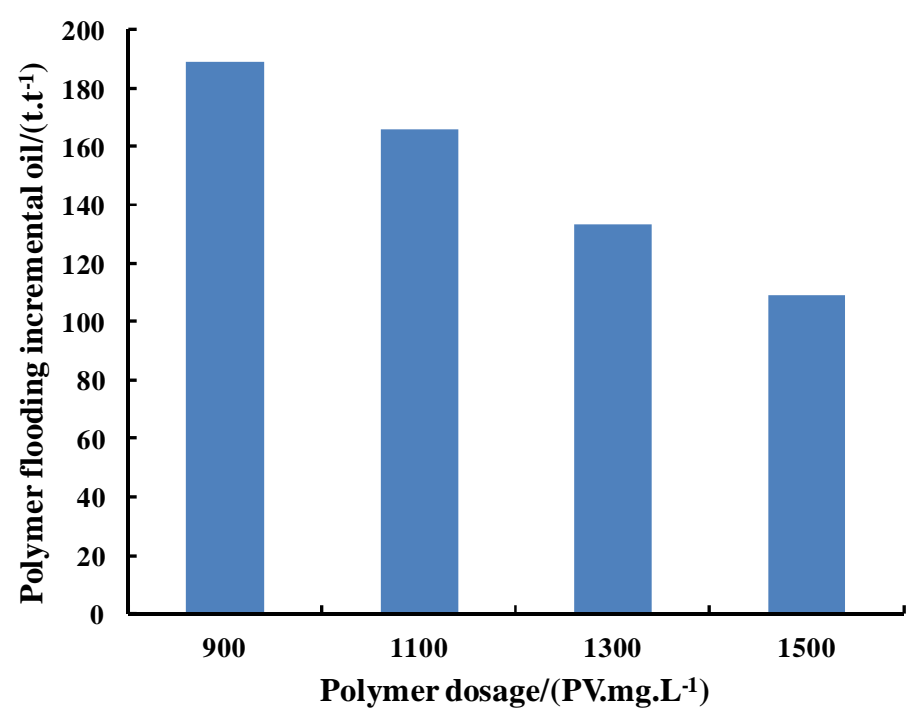

Fig.3 Relationship between polymer flooding incremental oil and polymer dosage

From what has been discussed above, considering rise scope of recovery efficiency, polymer flooding incremental oil and other technical indexes, polymer dosage of class I reservoir is 1100 PV.mg/L[13].

\section{Polymer Flooding Parameters of Class II Reservoirs}

In order to study polymer flooding parameters of class II reservoirs, we take sanan oilfield as an example[14].

Concentration of Polymer Solution. If polymer dosage is same, but concentration of polymer solution is different, the final displacement characteristics are different. In order to study the relationship between displacement characteristics and concentration of polymer solution, in the condition of injection rate is $0.14 \mathrm{PV} / \mathrm{a}$ and polymer dosage is $640 \mathrm{PV} . \mathrm{mg} / \mathrm{L}$, concentration of polymer solution is designed as $400 \mathrm{mg} / \mathrm{L}$ to $1400 \mathrm{mg} / \mathrm{L}$. With the increase of concentration of polymer solution, decrease of water cut ahead of schedule, decrease scope of water cut become apparent. If concentration of polymer solution is $1400 \mathrm{mg} / \mathrm{L}$, compared with the concentration of $800 \mathrm{mg} / \mathrm{L}$, recovery efficiency increase by $0.47 \%$, polymer flooding incremental oil is 4.4 ton, when water cut reached $98 \%$, water is saved by $0.21 \mathrm{PV}$. Therefore, in terms of technical effect, in the process of oil displacement, we should adopt high concentrations of slug. However, with the increase of concentration of polymer solution, the viscosity of polymer solution increased. It is also more difficult to inject polymer solution. Compared with class I reservoir, class II reservoir heterogeneity become obvious. Therefore, concentration of polymer solution of class II reservoir should different from that of class I reservoir. Design of concentration of polymer solution should depend on actual injection capacity of each well group, and performance index of selected polymer solution. Concentration of polymer solution is closely related to proportion of channel sand. The greater the proportion of channel sand, the bigger the selective space of concentration of polymer solution.

Therefore, considering reservoir heterogeneity, proportion of channel sand, polymer flooding control degree, pressure remaining space of polymer flooding and other factors, concentration of polymer solution of class II reservoir is $1000 \mathrm{mg} / \mathrm{L}[14]$.

Relative Molecular Weight of Polymer. In view of geologic characteristic of class II reservoir, when study relative molecular weight of polymer, firstly, relative molecular weight of polymer should as high as possible. So recovery efficiency can be enhanced and polymer dosage can be decreased. 
Secondly, the matching relationship between weight of polymer and different permeability of reservoir should be considered, the better polymer flooding effect can be obtained.

Through the research results of matching relationship, also, in the process of optimize relative molecular weight of polymer by using polymer flooding control degree, many experience are accumulated. A series of laboratory experiment also carried out to optimize relative molecular weight of polymer. Therefore, relative molecular weight of polymer of experimental area (class II reservoirs) is designed as $1.2 \times 10^{7}$ to $1.6 \times 10^{7}[14,15]$.

Injection Rate of Polymer Solution. In the process of optimize reasonable injection rate of polymer solution, two aspects should be considered. In one hand, limit of injection capacity of reservoir should be considered. In the other hand, we should guarantee selected injection rate of polymer solution can maintained normal production, develop period can be shortened and overall economic benefits of block can be improved. In the process of polymer solution injection for class II polymer solution, injection pressure is too high. It is difficult to inject polymer solution. Therefore, in the process of optimized injection rate of polymer solution of class II reservoir, the main considered factors are reasonable rise scope of pressure and polymer flooding control degree.

Finally, injection rate of polymer solution of class II reservoir is $0.14 \mathrm{PV} / \mathrm{a}[16]$.

Polymer Dosage. Through theoretical research and practical development, the result show that with the increase of polymer dosage, the decrease scope of water cut increased and the rise scope of recovery efficiency increased. However, because of the increase of polymer dosage, the utilization ratio of polymer solution declined. Therefore, we should consider both technology and economy, so the rise scope of recovery efficiency and polymer flooding incremental oil are great.

Therefore, polymer dosage of class II reservoir is 640 PV.mg/L[17].

Producer Injector Spacing. Channel sand of class II reservoir become narrow. The development area of poor permeability and fringe are lager. Therefore, if the producer injector spacing of class II reservoir keep for 250 meters, polymer flooding control degree is low. Relationship between polymer flooding control degree and producer injector spacing is shown in Table 1. Producer injector spacing of western of north one-two rows and the west of the second north block are 250 meters, polymer flooding control degree is lower than $70 \%$ of returning class II reservoir. When producer injector spacing is declined to 175 meters, polymer flooding control degree is increased by $8 \%$ to $10 \%$, polymer flooding control degree is more than $70 \%$. When producer injector spacing is declined to 150 meters, polymer flooding control degree is increased by $8 \%$ to $10 \%$, polymer flooding control degree is more than $80 \%$. When producer injector spacing is declined to 125 meters, rise scope of polymer flooding control degree is lower than $4 \%$. Therefore, the advisable producer injector spacing is 150 meters to 175 meters[14].

Table 1 Relationship between polymer flooding control degree and producer injector spacing

\begin{tabular}{c|c|c|c|c|c}
\hline \multirow{2}{*}{ Blocks } & $\begin{array}{c}\text { Producer } \\
\text { injector spacing }\end{array}$ & \multicolumn{4}{|c}{ Polymer flooding control degree(\%) } \\
\cline { 2 - 5 }$(\mathrm{m})$ & One-way & Two-way & Multi-way & \multirow{2}{*}{ Total } \\
\hline \multirow{2}{*}{$\begin{array}{c}\text { Western Part of B1 } \\
\text { and B2 }\end{array}$} & 250 & 29.4 & 24.5 & 7.5 & 61.4 \\
\cline { 2 - 5 } & 175 & 16.5 & 17.7 & 37.1 & 71.3 \\
\hline \multirow{2}{*}{$\begin{array}{c}\text { Eastern Part of B1 } \\
\text { and B2 }\end{array}$} & 125 & 13.8 & 22.8 & 50.5 & 87.1 \\
\cline { 2 - 6 } & 250 & 30.2 & 26.0 & 12.3 & 68.5 \\
\hline \multirow{2}{*}{$\begin{array}{c}\text { Western north II } \\
\text { region }\end{array}$} & 175 & 8.0 & 28.2 & 39.7 & 75.9 \\
\cline { 2 - 5 } & 125 & 14.0 & 24.8 & 50.3 & 89.1 \\
\cline { 2 - 5 } & 175 & 18.8 & 25.3 & 17.5 & 68.5 \\
\hline \multirow{2}{*}{$\begin{array}{c}\text { Western north II } \\
\text { region }\end{array}$} & 125 & 13.9 & 23.3 & 52.1 & 79.2 \\
\cline { 2 - 5 } & 175 & 25.6 & 27.5 & 13.3 & 90.0 \\
\hline
\end{tabular}


Currently, in Daqing oilfield, producer injector spacing of class III is between 100 meters and 125 meters[14,18].

\section{Polymer flooding parameters of class III reservoirs}

In order to study polymer flooding parameters of class III reservoirs, we take Eastern of Southern Fourth Block as an example [13].

Concentration of Polymer Solution. The results of numerical simulation show that when mobility ratio is greater than 1 and polymer dosage is same in different schemes, oil displacement effect have little relationship with concentration of polymer solution. With the increase of concentration of polymer solution, decrease of water cut ahead of schedule, decrease scope of water cut become apparent. Development period declined. In the other hand, with the increase of concentration of polymer solution, viscosity of polymer solution is also increased. Which can lead to the increase of injection pressure, it is different to inject polymer solution. Therefore, in the process of optimize concentration of polymer solution of class III reservoir, viscosity of polymer solution and injection pressure should be considered.

There is relationship between viscosity of polymer solution and quality of injection water. In order to obtained good effect, viscosity of well head is $12 \mathrm{mPa}$.s to $17 \mathrm{mPa}$.s, in the condition of meet the need of this viscosity, concentration of polymer solution of class III reservoir is $800 \mathrm{mg} / \mathrm{L}$ to $1000 \mathrm{mg} / \mathrm{L}[13,18]$.

Relative Molecular Weight of Polymer. In terms of Eastern of Southern Fourth Block, its permeability is low. Thickness of layer is great. It has many layers and the change of permeability is great. Therefore, in the process of optimize relative molecular weight of polymer, we should guarantee large amount of polymer solution injected into thin and lower penetrability layers. If relative molecular weight of polymer is $5 \times 10^{6}$, the layers number of meet the standard of polymer flooding is 6 in pu II. Polymer flooding control degree is greater than $50 \%$, proportion of valid thickness is more than $70 \%[18,19,20]$.

Therefore, relative molecular weight of polymer of class III reservoir is $5 \times 10^{6}[13,18,19,20]$.

Injection Rate of Polymer Solution. The research results show that with the increase of injection rate of polymer solution, recovery efficiency slightly declined. In practice, there is close relationship between injection rate and injection pressure. Therefore, in the process of optimize injection rate of polymer solution, injection pressure of injection well should not more than collapse pressure of reservoir. Collapse pressure of this block is $11.0 \mathrm{MPa}$ to $11.5 \mathrm{MPa}$. In the process of polymer flooding, injection pressure should leave certain spacing. Combined the injection capacity of experimental area, injection rate of polymer solution of class III reservoir is $0.25 \mathrm{PV} / \mathrm{a}[19,20,21]$.

Polymer Dosage. In terms of Eastern of Southern Fourth Block, in the condition of its injection rate of polymer solution is $0.2 \mathrm{PV} / \mathrm{a}$ and concentration of polymer solution is $800 \mathrm{mg} / \mathrm{L}$. We make a research on the main indexes of oil displacement effect in different polymer dosage. Finally, polymer dosage of class III reservoir is 570mg/L.PV.[21,22,23]

Tab.2 The impaction on oil displacement effect with different polymer dosage

\begin{tabular}{c|c|c|c}
\hline $\begin{array}{c}\text { Polymer dosage } \\
(\mathrm{mg} / \mathrm{L} . \mathrm{PV})\end{array}$ & Recovery efficiency(\%) & $\begin{array}{c}\text { Rise value of recovery } \\
\text { efficiency }(\%)\end{array}$ & $\begin{array}{c}\text { Polymer flooding } \\
\text { incremental oil } \\
(\mathrm{t} / \mathrm{t})\end{array}$ \\
\hline 570 & 9.75 & 7.09 & 70.6 \\
\hline 640 & 10.4 & 7.74 & 68.7 \\
\hline 670 & 10.6 & 7.94 & 67.2 \\
\hline
\end{tabular}

Producer injector spacing. Polymer flooding control degree has critical influence on polymer flooding effect. When producer injector spacing declined from 250 meters to 175 meters, polymer flooding control degree is increased by $8 \%$ to $10 \%$. When producer injector spacing declined from 175 meters to 125 meters, polymer flooding control degree is increased by $8 \%$ to $10 \%$ again. Therefore, the 
way of decline producer injector spacing is useful for the increase of polymer flooding control degree[24,25,26,27].

\section{Polymer Flooding Effect of Daqing Oilfield}

Compared with water flooding, after polymer flooding, water content of class I reservoir reduces about $20 \%$, and the recovery efficiency increases about $10 \%[28,29,30]$.

Class II reservoir of upward movement of test site in the middle block of southern third region, when injection pore volume multiple is $0.023 \mathrm{PV}$, composite water cut of the whole region would be the biggest about $94.3 \%$. When injection pore volume multiple is $0.035 \mathrm{PV}$, the whole region would begin to become effective. When injection pore volume multiple is $0.276 \mathrm{PV}$, composite water of the whole region would be the lowest about $76.6 \%$, water cut declined by $17.7 \%$. When injection pore volume multiple is $0.64 \mathrm{PV}$, finishing injecting polymer solution turns into subsequent water-flooding in the whole region. When composite water cut of the whole region is $98 \%$ and composite injection pore volume multiple is $1.016 \mathrm{PV}$, at the moment, the stage of polymer flooding of recovery percent of reserves is $17 \%$, the whole region of ultimately recovery efficiency is $49.6 \%$, expected then ultimately cumulative oil production is about $8.7193 \times 10^{4} \mathrm{t}$. Compared with water drive, class II reservoir of polymer flooding of water cut declines by $11 \%$, while recovery efficiency increases by $7.8 \% \cdot[31,32,33]$

Class III reservoir of polymer flooding of test site in Daqing oilfield put into production in the second half of 2004, and then the group of single well began to try to water flooding in eastern north II region and the center west in December 2004. Injects relative molecular of polymer that is $300 \times 10^{4}$ in eastern north II region, now, mass concentration of polymer is $800 \mathrm{mg} / \mathrm{L}$, viscosity of liquid is $7.0 \mathrm{mPa} . \mathrm{s}$ at wellhead, and pressure injection keeps in $12.7 \mathrm{MPa}$; compared with finishing water drive, injection pressure rises by $3.5 \mathrm{MPa}$, while the value of upside potential is $1.1 \mathrm{MPa}$ to bursting pressure[34,35]. Injects relative molecular of polymer that is $500 \times 10^{4}$ in the center west, now, mass concentration of polymer is $800 \mathrm{mg} / \mathrm{L}$, viscosity of liquid is $10.0 \mathrm{mPa}$.s at wellhead, and pressure injection is $11.0 \mathrm{MPa}$, while the value of upside potential is $1.5 \mathrm{MPa}$ to bursting pressure[36]. Now, water content of Class III reservoir reduces by $6 \%$, recovery efficiency increase by more $5 \%$ on the basis of condition of polymer injection[37].

\section{Conclusions}

(1) Class I reservoir was put into production for polymer flooding at first stage. Concentration of polymer solution is $2000 \mathrm{mg} / \mathrm{L}$ and relative molecular weight of polymer is $2.5 \times 10^{7}$. Polymer dosage is 1100 PV.mg/L and injection rate is 0.12 PV/a. Injection-production well spacing is between 200 meters and 250meters.

(2) Class II reservoir was put into production with polymer flooding at second stage. Concentration of polymer solution is $1000 \mathrm{mg} / \mathrm{L}$ and relative molecular weight of polymer is between $1.2 \times 10^{7}$ to $1.6 \times 10^{7}$. Polymer dosage is $640 \mathrm{PV} . \mathrm{mg} / \mathrm{L}$ and injection rate is $0.14 \mathrm{PV} / \mathrm{a}$. Injection-production well spacing is between 150 meters and 175 meters.

(3) Class III reservoir was put into production with polymer flooding at third stage. Concentration of polymer solution is between $800 \mathrm{mg} / \mathrm{L}$ to $1000 \mathrm{mg} / \mathrm{L}$ and relative molecular weight of polymer is $5 \times 106$. Polymer dosage is $570 \mathrm{PV} . \mathrm{mg} / \mathrm{L}$ and injection rate is $0.25 \mathrm{PV} / \mathrm{a}$. Injection-production well spacing is between 100 meters and 125 meters.

(4) Perfect achievement from polymer flooding is acquired. Compared with water flooding, water cut is declined by $20 \%$ to the maximum, and recovery efficiency is increased by $10 \%$ for polymer flooding of class I reservoir. Water cut is declined by $11 \%$ to the maximum, and recovery efficiency is increased by $7.8 \%$ for polymer flooding of class II reservoir. Water cut is declined by $6 \%$ to the maximum, and recovery efficiency is increased by $5 \%$ for polymer flooding of class III reservoir. 


\section{References}

[1] J.G.Soutnwick,C.W.Manke. Molecular degradation, injectivity, and elastic properties of polymer solutions[R].SPE,1988, 4: 1193-1201.

[2] R.D.Hester, L.M.Flesher, C.L.Mc Cormick.Polymer solution extension viscosity effects during reservoir flooding[R].SPE/DOE27823,1994.

[3] M.Ranjbar,J.Rupp,G.Pusch,R.Meyn.Quantification and optimization of viscoelastic effect of polymer solutions for enhanced oil recovery[R].SPE/DOE24154,1992.

[4] Xue S.C., Phan-Thien N., Tanner RI.Numerical study of secondary flows of viscoelastic fluid in straight pipes by an implicit finite volume method[J]. J Non-Newtonian Fluid Mechanics, 1995,59(2):191-213

[5] Xin Ping Li, Li Yu, Yong Qiang Ji, Bo Wu, Gan Zuo Li and Li Qiang Zheng, New type flooding systems in enhanced oil recovery, Chinese Chemical Letters Volume 20, Issue 10, October 2009, Page 1251-1254

[6] Harvey AH, Menzie DE. Polymer solution flow in porous media[J]. SPE Journal, June 1970:111-117.

[7] Pyce DJ. Improved secondary recovery by control for water mobility[J]. J.P. Tee, Aug. 1964: 911-916.

[8] Li Meng. Study on the Optimization of High-concentration Polymer flooding of the First-order Oil Reservoir at the Late Stage of Polymer Flooding in Sabei Development Block[M]. 2010.3.

[9] Yao Yu. Study on the Methods to Improve Oil Recovery after Polymer Flooding in First-order Reservoir [M]. 2013.6.

[10] Xu Zhengshun, Niu Jingang, Liao Guangzhi. Application and experience of polymer flooding in Daqing oil field[J]. Petroleum Geology \&Oilfield Development in Daqing. 2000, 19(4):13-19.

[11] LIAO Guang-zhi , NIU Jin-gang,. Shao Zhen-bo, Chen Peng. Application and experience of industrialized polymer $\mathrm{f}$ looding in Daqing oilf ield[J]. Petroleum Geology\&Oilfield Development in Daqing, 2004, 23(1): 48-52.

[12] Niu Jingang . Practices and understanding of polymer flooding enhanced oil recovery technique in Daqing oilf ield[J]. Petroleum Geology \&Oilf ield Development in Daqing. 2004, 23(5):91-93.

[13] XU Dongfang. Technical studies on polymer flooding of being back to reservoirs for Sub-layers and third type of layers in Daqing Oilfield[M]. 2008.4.

[14] Sun Weiguo. Research of polymer flooding technique in class II reservoir of Sannan oil field in Daqing [M]. 2010.6.

[15] ZHANG Xiao-qin, GUAN Heng Methods to Improve Development Results of Polymer Flooding in Class II Reservoirs [J]. Petroleum Geology \& Oilfield Development in Daqing. 2005,24(4). 81-83.

[16] Han Jie, Yuan Yuan, Du Yijing, Wang Yan, Wang Fenggang. The research of integrated adjustment technology and estimate of development effect of polymer flooding in class II reservoir[J]. China Mining Magazine. 2010, 19: 183-186.

[17] WANG De-min, CHENG Jie-cheng, WU Jun-zheng, WANG Gang. Application of polymer flooding technology in Daqing Oilfield[J]. Acta Petrolei Sinica.2005, 26(1): 74-78.

[18] ZHANG Xiao-qin, GUAN Heng, WANG Hong-tao Practice of tertiary-main layers polymer flooding in Daqing Oilfield[J]. Petroleum Exploration and Development. 2006, 33(3):374-377. 
[19] Li Jie, Zhang Shanyan. Oillayer classification for LaSaXing oilfields at high water cut stage[J]. Petroleum Geology \& Oilfield Development in Daqing. 2007, 26(6): 86-90.

[20] Liu He. Current Situation And Prospect For oil recovery techniques after polymer flooding in Daqing Oilfield [J]. Oil Drilling \& Production Technology. 2008, 30(3):1-6.

[21] Zhang Tao. Study on different factors affect oil displacement of the polymer system [M]. 2014.6.

[22] Han Bing. Studys on enhanced oil recovery by high concentration polymer flooding in Daqing Oilfield[M] 2013.3.

[23] Sun Linghui. The Chemical Flooding Further Enhances Oil Recovery Method Research After Polymer Flooding [M]. 2005.3.

[24] Cheng,K.H,:Chemical Consumption During Alkaline Flooding:A comparative,Paper SPE14944 presented at the 1986 SPE/DOE,Tulsa.April 20-23

[25] Bazin,B., Yang Chang-Zhi,et al,:Micellar Flooding in an Alkaline Environment Under Lav Junmion Conditions. SPE22363,92 SPE Mar.23-31,1992,Beijing.

[26] Mungan,N.:Enhanced Oil Recovery Using Water as a Driving Fluid-Part4: Fundamentals of Alkaline Flooding,World Oil (June 1981) 209-20

[27] K.Walters,D.M.Jones.The extensional viscosity behavior of polymeric liquids of use in EOR[R].SPE18497,1989.

[28] R.Haas,F.Durst.Viscoelastic flow of dilute Polymer solutions in regularly packed beds[J].Rheologica Acta,1982,21:566-571.

[29] J.Heemskerk,R.Janssen-van Rosmalen,R.J.Holtslag,D.Teeuw.Quantification of Viscoelastic Effects of Polyacry Lamide Solution[R].SPE/DOE12652,1984.

[30] J.Vorwek,P.O.Brunn. Shearing effects for the flow of surfactant and polymer solutions through a packed bed of spheres[J].Journal of Non-Newtonian Fluid Mechanics, 1994,51:79-95.

[31] Wang Demin,Xia Huifen,Liu Zhongchun,et al.Study of the mechanism of polymer solution with visco-elastic behavior increasing microscopic oil displacement efficiency and the forming of steady "oil thread" flow channels[R].SPE68723,2001.

[32] Jia Shihua. The research for internal arhchi of the P I 1-4 layers which is in the test area after polymer flooding of the beiyi block first class layers [M]. 2014.3.

[33] William AD.Erica $\mathbf{J}$ W.Adsorption of Hexadecyltrirnethylam onium Brom ideto Miex Nanometer-Scale Studyof Binding-Site Competition Effects[J].SPE,1999.

[34] Wang Demin,Cheng Jiecheng,Yang Qingyan,et al.Viscous-elastic polymer can increase microscale displacement efficiency in cores[R].SPE63227,2000.

[35] PANG Changying, XU Guosong, WANG Zhijiang, etal. Technologies to enhance recovery factor after polymer flooding in Henan oilfield[ J] .Henan Petroleum, 2002,16(5):1 -3.

[36] PENG Hongli, ZHOU Xiaoping, YAO Guangju, etal. Laboratory research on microscopic distribution of residual oil after polymer driving and how to improve recovery factor for reservoirs with big porous channels [J]. Natural Gas Exploration and Development, 2005, 28(3):1 -4.

[37] LIU Mingyi, WANG Yefei, CUI Ya, etal.Research on technology of EOR after polymer flood[ J] .Fault-Block Oil and Gas Field, 2006, 13(1):2 -3. 